\title{
Implementation of Lean Six Sigma (LSS) Techniques in Small and Medium Enterprises (SMEs) to Enhance Productivity
}

\author{
Abdulrakeeb A. Ghaleb ${ }^{1}$, Mahmoud A. El-Sharief ${ }^{1}$, Mohamed. G. El-Sebaie ${ }^{1}$ \\ ${ }^{I}$ (Department of Mechanical Engineering, Faculty of Engineering / Assiut University, Egypt)
}

\begin{abstract}
In today's world, business has become additional competitive. All industries and organizations have to perform well so as to survive and be profitable. The lean six sigma (LSS) methodology is being applied extensively to tackle many qualities connected issues in many processes of today's industries. A cement paper bags could be a packaging sack manufactured from paper high quality and frequently craft virgin fiber, that sometimes consists of many layers to provide strength, with high physical property and high tear resistance. This study is interested in implementing the lean six sigma (LSS) methodology in SMEs. The contribution of this analysis is using LSS methodologies to reduce waste of time, reduce of defects, and increase the level of sigma. The obtained results when implementation LSS methodology within the application of the cement bags industry indicate that the production rate may well be increased about 4.25 attempt to additionally may well be in save of around \$ 8,952 from reduction of waste time and \$12,730.61 from defects reduction; the full is \$21,682.61 annually. additionally, the preparation time might be reduced by about $4.57 \%$, increase the OEE by $20 \%$, and the level of sigma could be increase to 4.00 .
\end{abstract}

Keywords: cement bags, Lean six sigma (LSS), DMAIC, SMEs, OEE)

\section{Introduction}

Companies seek for ways in which to enhance their production and manufacturing processes so as to stay competitive within the market to reduce cost, enhance productivity and improve product quality. Therefore, companies should utilize all the obtainable resources with efficiency so as to cater their customers with high quality product at a low value.

The lean six sigma (LSS) rising with the mixture of lean manufacturing processes within the early 1960s and also the six sigma generated by Motorola is that the last evolution step within the manufacturing history. each application give to achieve operational effectiveness. this suggests to use changes adding value, to method right at the primary time and to act quickly and with efficiency. Lean manufacturing focuses on eliminating loss in method and reducing the complexness. [1-2].

LSS aims to develop solutions by using the minimum quantity of resources (human, material and capital) and to create the product reach customers on time. Six sigma provides quality philosophy and could be an applied mathematics tool to observe process performance. It aims to reduce the variability within the process and to eliminate defects. Lean manufacturing and 6 sigma work along with success. whereas detective work lean tools, the issues in flow and valueless activities, six sigma will increase the proficiency of every step adding value and forms a second entry in lean manufacturing techniques. particularly in non-production processes, each merging six sigma with lean tools and properly differentiating the appliance, tools and techniques with educational content for the service sector and support processes are essential [3-4]. The integration of each (LSS) technique can facilitate the accomplishment of zero defect producing in organizations complemented by the elimination of non-value additional activities, that ends up in bigger results than either system is able to do alone [3][5].

This study focuses in implementing the lean six letter (LSS) in SMEs. The LSS proposed during this study is completely different from alternative LSS framework supported alternative initial studies in terms of the main target of LSS implementation in SMEs solely. This study contributes the appliance of LSS techniques in SMEs to eliminate the time waste, defects and enhanced the level of sigma.

\section{Lean Six Sigma (LSS)}

Lean six sigma (LSS) is an approach targeted on improving quality, reducing variation and eliminating waste in a company. it's supported the ideas of combining two improvement programs, six sigma and lean manufacturing, additionally called lean enterprise. Six sigma is both a high quality management philosophy and a technique that focuses on reducing variation, measurement defects and up the quality of product, processes, and services[1][6-7] Table 1 presents the survey of lean six sigma LSS studies and presents the topic and the sector of each research [8][4]. 
Implementation of Lean Six Sigma (LSS) Techniques in Small and Medium Enterprises (SMEs) to ..

Table 1: Lean Six Sigma (LSS) studies in sectors and topics[9-10]

\begin{tabular}{|l|l|l|}
\hline \multicolumn{1}{|c|}{ Authors } & \multicolumn{1}{c|}{ Sector } & \multicolumn{1}{c|}{ Topic } \\
\hline Furterer 2004 & Service- financial & Implementation - reduce the cycle time \\
\hline Stephen 2004 & Industry & Implementation -reduced the defects \\
\hline Chen et al. 2005 & Industry-Automobile & Improvement of manufacturer's quality \\
\hline Kumar et al. 2006 & Industry- casting & Reduce the defect occurring in the final product \\
\hline Cronemyr 2007 & Industry (service) Electronic & Implemented to problem solving in Siemens \\
\hline Ramamoorthy 2007 & Industry- Aircraft & Implementation - reduction the rework time \\
\hline Koning 2007 & Service - investment & Implemented - reducing operational cost \\
\hline Chandler 2007 & Industry & Improvements both time and money savings \\
\hline Nuce et al. 2008 & Service- pharmacy & Implementation -waste reduction \\
\hline Martell-rojas 2010 & Service - Hospital & Implementation -to be better services \\
\hline Kellogg 2010 & Service- health care & Implemented -investigate the financial benefits \\
\hline Alyamoor 2010 & Industry- wear factory & Implementation -reduced the costs of defects \\
\hline Barnala 2011 & Industry- Recycle & Implementation - optimizing process and remove errors \\
\hline Hale 2011 & Industry-transformation & Implementation- reduce waste \\
\hline Atmaca et al. 2011 & Industry- Dishwashers & Increase profit \\
\hline Patel 2011 & Industry-Small packaging & Implemented -improve Lean Six Sigma standards to meet USA \\
\hline Basavaraj et al. 2011 & Industry- steel & Reduce variation and improve yield \\
\hline Sabeeh et al. 2012 & Industry- Medical Syringes & Increase sigma level, reduce damaged product \\
\hline Cournoyer et al. 2013 & Service-environment & Improve make decisions \\
\hline Abdullah, 2013 & Industry- drugs & Implementation -reduced the defects \\
\hline Mandahwi et al. 2012 & Industry- printing & Application LSS- increase effectiveness \\
\hline Ren Jie et al. 2014 & Industry- printing & Implementation -reduced waste and variation \\
\hline
\end{tabular}

\section{Lean Six Sigma (LSS) Framework}

The LSS framework has 5 phases as shown in fig. 1 with every phase providing a structural guide towards root-cause identification of a problem, therefore proposing and implementing cement bags to eliminate the root cause through preparation time and reduce defects. It ought to be noted that this framework is that the technique that may be utilized in LSS adoption [11-12].

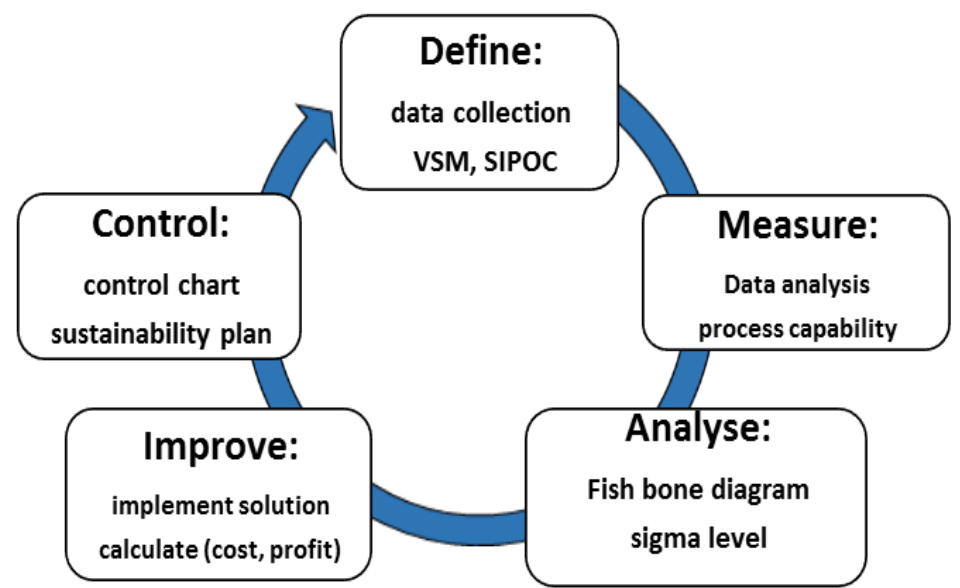

Fig. 1: Lean Six Sigma implementation in SMEs

The LSS framework as shown in fig. 1 is really a simplification of the six sigma's DMAIC methodology with guided steps on utilizing certain lean tools in every phase. The framework utilizes data driven and guided standard approach of the six sigma DMAIC methodology whereas utilizing lean tools in every phase to see improvement opportunities and additional analyze the problem (s) [13-16].

\subsection{Phase 1: Define the problem}

In this part of a lean six sigma (LSS), the outlines of the cement bags industry case study and its objectives should be clearly known. Cement bag manufacturing processes, and significantly the method studied during this paper, are typically comprised of 3 stages namely: 1st stage includes 5 steps, material setup, printing, glowing, tubing, and cutting. Second Stage includes 5 setups, feeding, opening, valve installation, gluing, closing, and assortment. Whereas third stage solely temporary inventory to drying the glue. These method steps are illustrated in fig. 2 . 


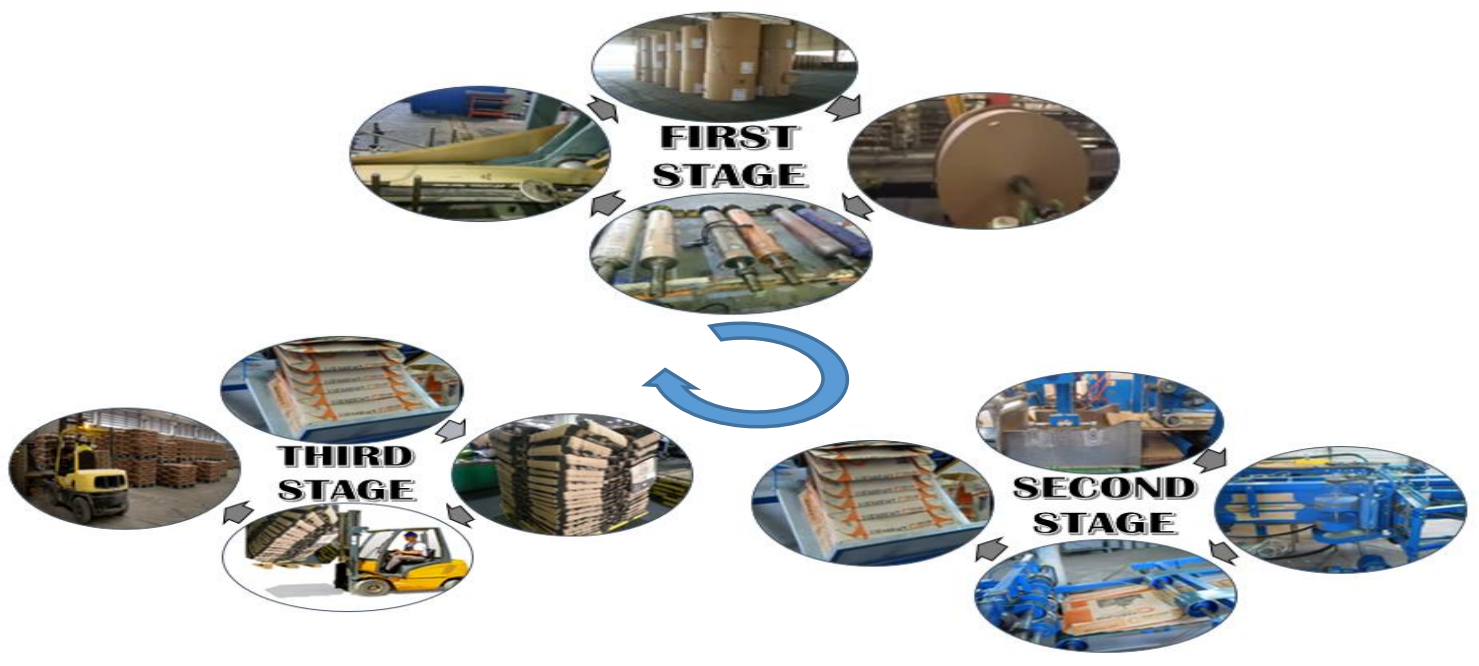

Fig. 2: Manufacturing processes of cement bags

The SIPOC (suppliers, inputs, process, outputs, and customers) process map is one among the most valuable tools. By employing a standard SIPOC diagram, to understanding the flow of knowledge, supplier, input, process, output and costumer demand of producing system. Fig. 2 shows the SIPOC diagram of cement bags industry, the supplier craft roll paper, ink, and glue to identify the flow processes to produce the cement bags. In order to have an insight into this state of the preparation time, a current value stream mapping (VSM) is formed which supplies a better look into the process in order that opportunities for improvement will be known. Fig. 3 shows the VSM, that shows the movement of materials through totally different manufacturing processes.

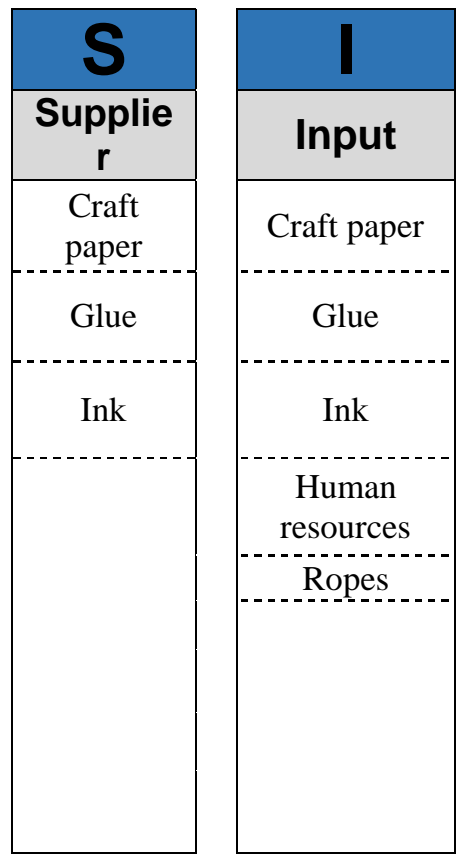

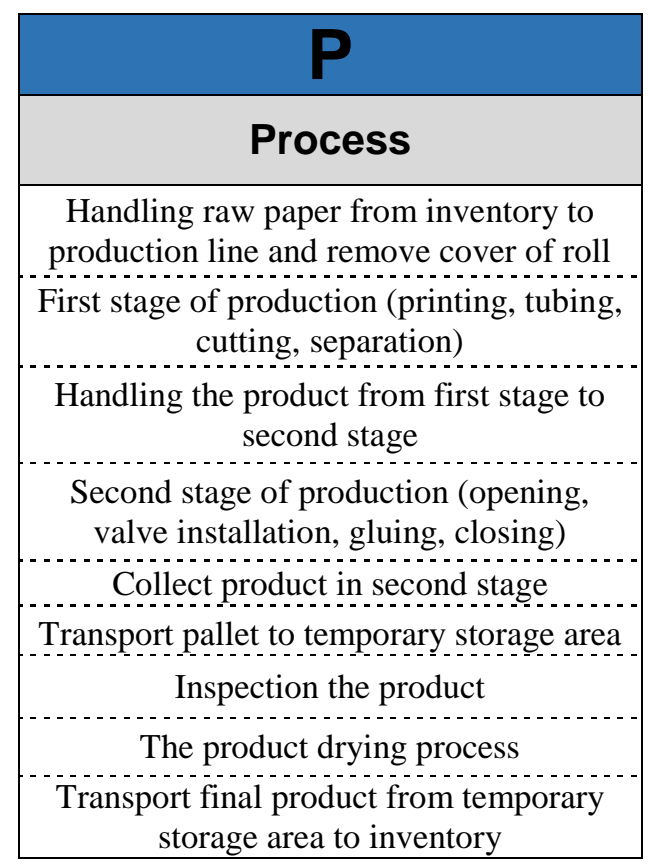

Fig. 3: SIPOC diagram of cement bags

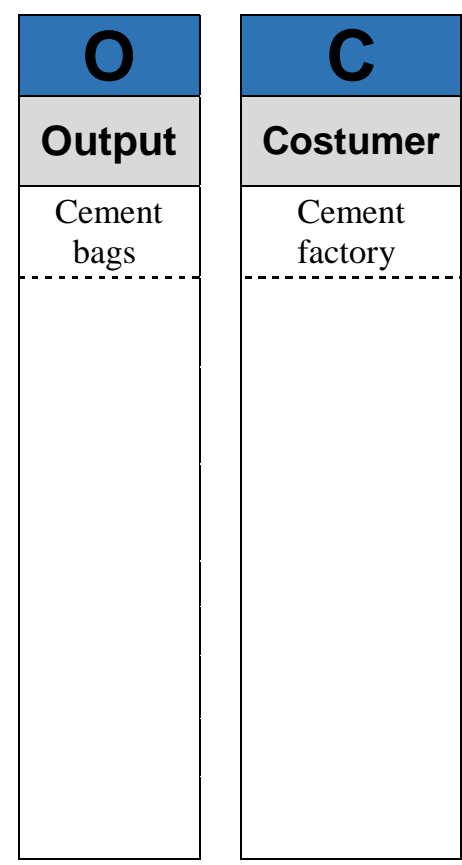

In addition, VSM in fig. 3 shows 3 preparations time before each stage. Preparation one is 48 secs that include transportation raw craft paper by fork lift, take away cover and set appear machine whereas preparation 2 is 36 secs that include collect semi-product and handling to second stage and also the last preparation time is $147.8 \mathrm{sec}$, transportation final product to temporary inventory. The preparation time 2 between 1 st stage and 2 nd stage cause to stop operating about $45 \mathrm{~min}$ at begin of shift till the semi-product in 1 st stage for $45 \mathrm{~min}$ or additional to produce 2 pallets. the table 2 shows the number of stops because of this case 
Table 2: Number of stops for second stage

\begin{tabular}{|c|c|c|c|}
\hline Month & No of stops & Total shift & ratio \\
\hline January & 13 & 45 & $28.89 \%$ \\
\hline February & 11 & 49 & $22.49 \%$ \\
\hline Average & 12 & 47 & $25.69 \%$ \\
\hline
\end{tabular}

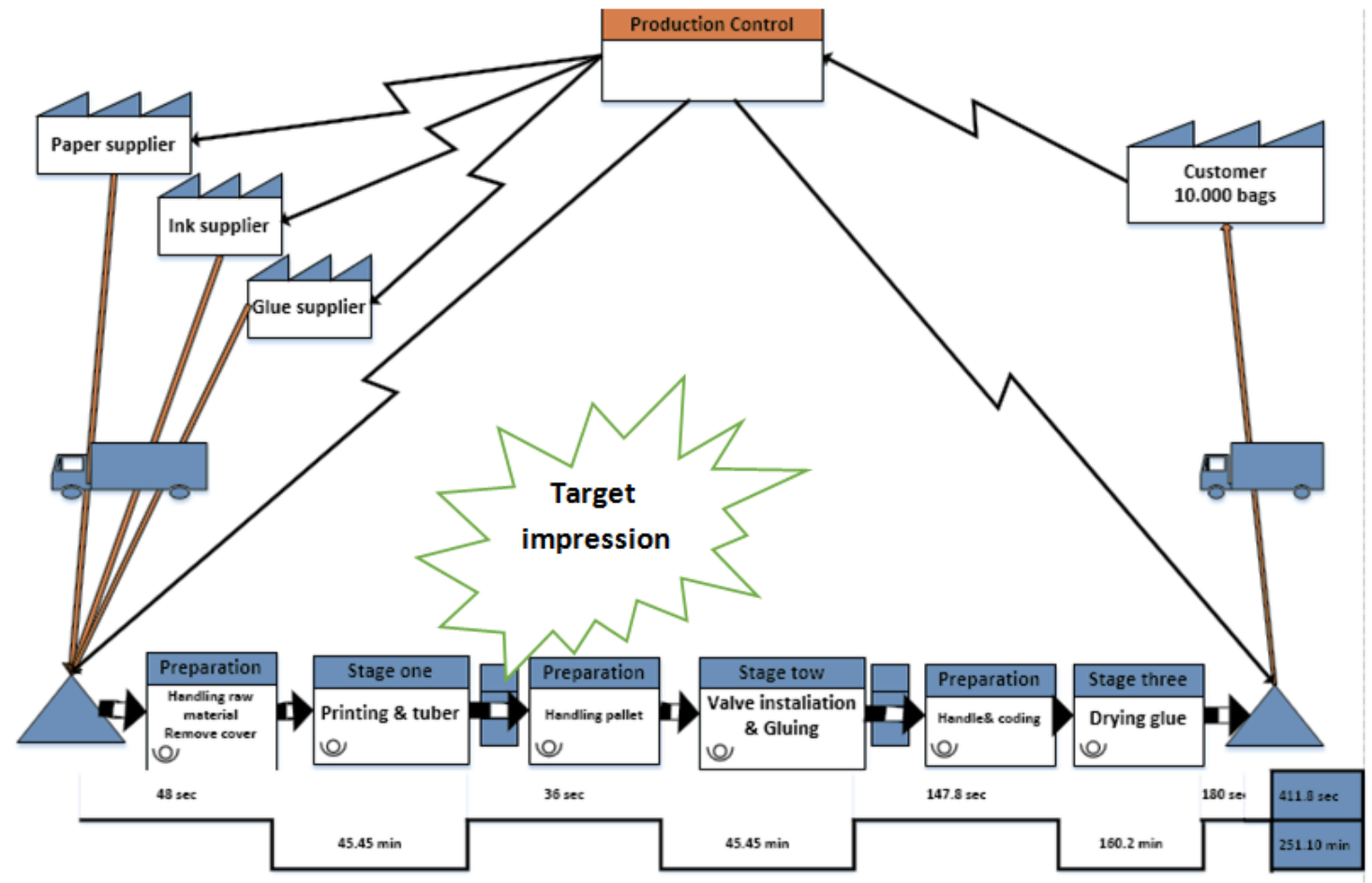

Fig. 4: Value Stream Mapping VSM of cement bags

The preparation time before second stage (valve installation) will be analyzed further to determine the root causes of its high setup time in the analyze phase.

\subsection{Phase 2: Measure - Data Analysis}

The current performance of the processes is measured to know the key process variables and identify the critical points in the length and width of cement bag from the measurement points that are regularly measured by the enterprise. The length and width of cement bag are $=60 \times 50 \mathrm{~cm}$, whereas the value width of two sides is $=9.50$ $\mathrm{cm}$. to analysis and evaluate this data using the MINITAB V.17 software. The graphical results of the dimensions for cement bag length and width are presented in fig. 5 and fig. 6 ,
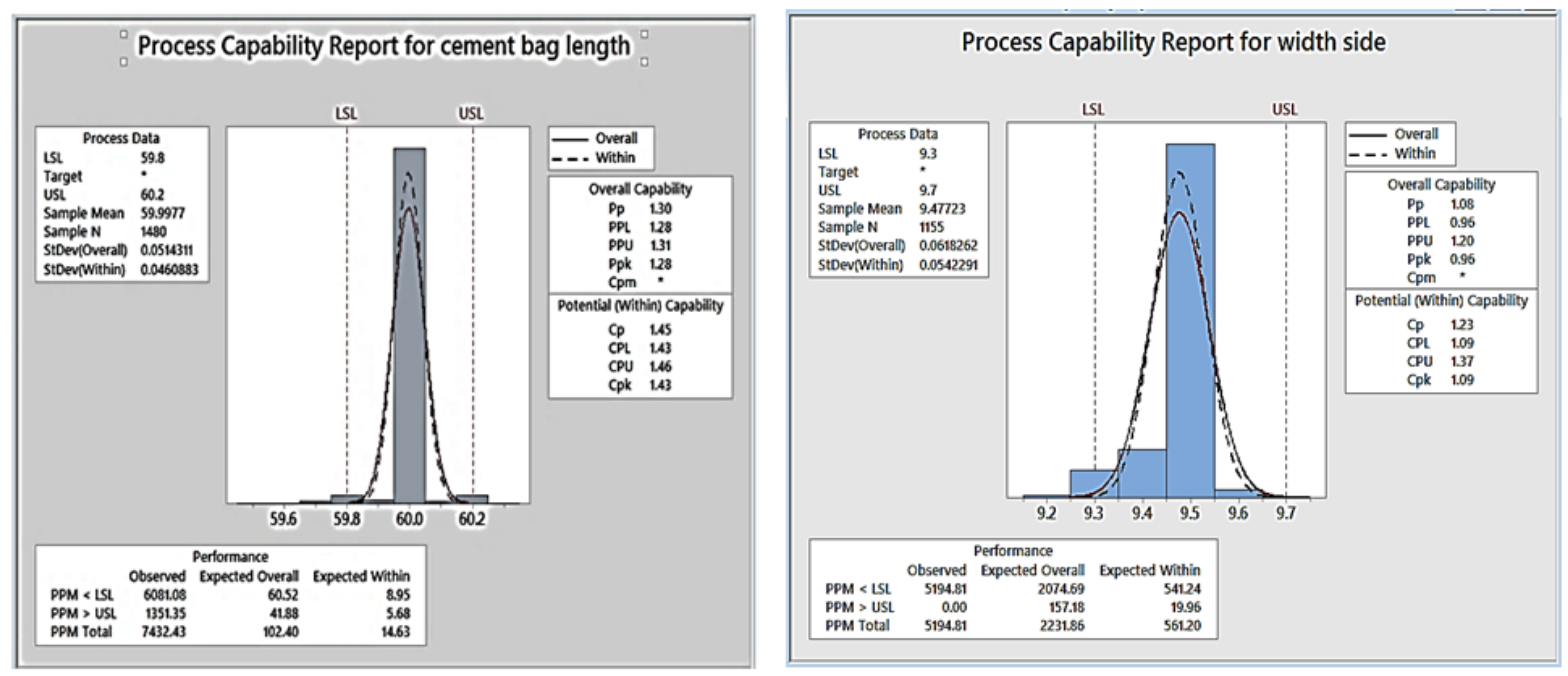

Fig. 5: Process capability of cement bags Length and width 

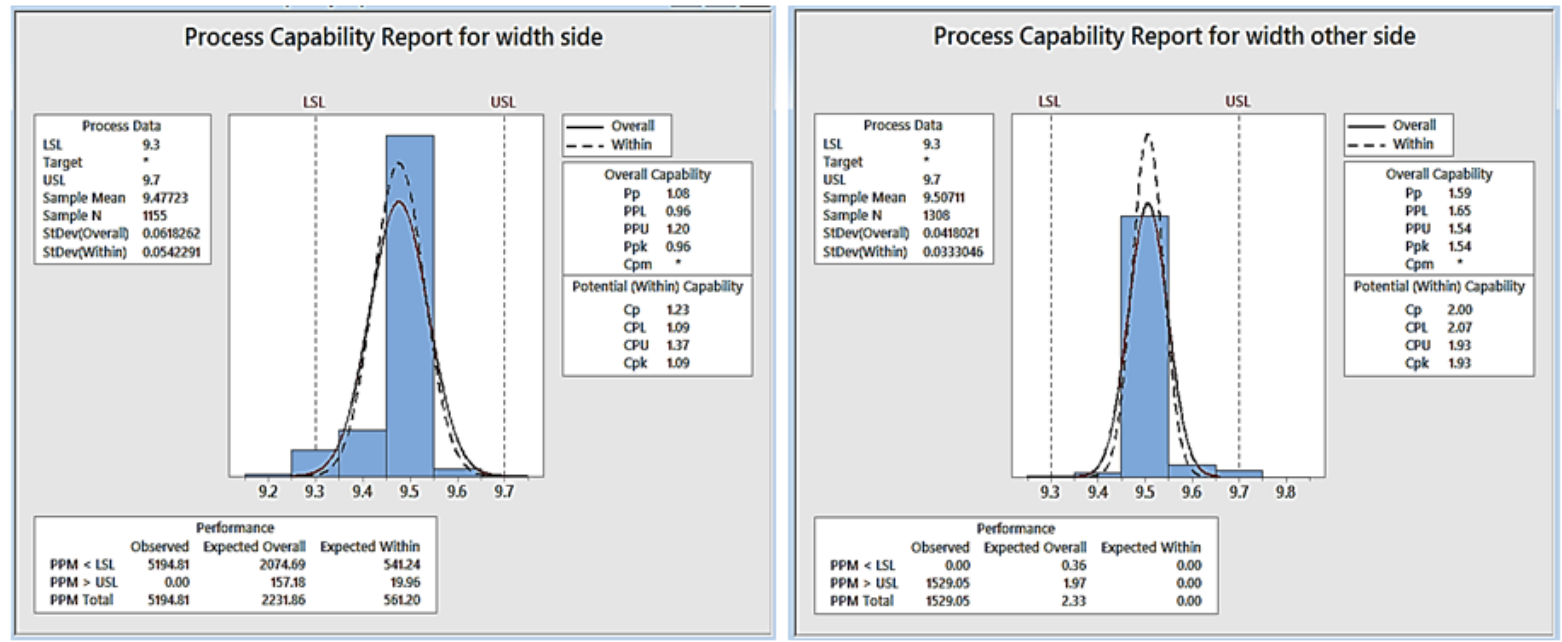

Fig. 6: Process capability of cement bags side and other side width

Fig. 5 (right side) show the sample average value of cement bag length $(59.997 \mathrm{~cm})$ is near USL $=$ $60.20 \mathrm{~cm}$ and $\mathrm{LSL}=59.73 \mathrm{~cm}$. the overall value of PPM within the right confirms with the most likely of 102.40 . Since the CPK (1.43) value is sort of over the target value (CPK > 1.33), whereas, in same fig. 6 (left side) shows the process capability of width that sample average value $(9.477 \mathrm{~cm})$ is near USL $=9.70 \mathrm{~cm}$ and $\mathrm{LSL}=$ $9.30 \mathrm{~cm}$. the overall value of expected within PPM just about 561.20 out of 1,000,000 won't meet the specification limits. Since the CPK (1.09) value is sort of lower the target value (CPK > 1.33). On other hand, the process capability of cement bags value side width that the sample average value $(9.477 \mathrm{~cm})$ is near USL $=$ $9.70 \mathrm{~cm}, \mathrm{LSL}=9.30 \mathrm{~cm}$. the overall value of expected within parts per million (PPM) around 561.20 out of $1,000,000$ won't meet the specification limits. Since the Cpk (1.09) price is kind of lower the target price (Cpk > 1.33 ) as shown in fig.6 (right side),

However, the left side of fig.7 shows the process capability of cement bag width other side, the sample average value $(9.507 \mathrm{~cm})$ is near USL $=9.70 \mathrm{~cm}$ and $\mathrm{LSL}=9.30 \mathrm{~cm}$. The $\mathrm{Cpk}(1.93)$ value is sort of over the target value (Cpk > 1.33), the overall value of expected overall parts per million (PPM) around 2.33 out of a million won't meet the specification limits, this process is fairly capable.

The cement bags outside the control limits cannot repair it, these bags become scrap after registration, but this bags doesn't have classification about defects and doesn't identify the causes of defects. The DPMO is 7984.88 defect with defects ratio is $0.799 \%$ and the level of accuracy in processes is $99.2 \%$ and the sigma level in this case is 3.91. Defects of the cement bags are given in table 3 .

Table 3: The defects of cement bags

\begin{tabular}{|c|c|c|c|}
\hline Month & Production & Defects & Defect ratio \\
\hline January & 7792640 & 62040 & $0.796 \%$ \\
\hline February & 8005980 & 64109 & $0.801 \%$ \\
\hline Average & 7899310 & 63075 & $0.799 \%$ \\
\hline
\end{tabular}

\subsection{Phase 3: Analyze}

Based on the observation within the production line of each preparation and setup, preparation time before second stage, that include collect semi-product and handling to second stage. the target of this part to work out the root causes of waste in preparation time and defects and establish the significant process parameters inflicting the defect.

Fig. 7 shows the cause and effect diagram of preparation time problem, the main focus of root-cause analysis can be allotted for setup of valve preparation. Fish bone diagram is developed supported each setup to help the findings of the cause of this problem. it's developed through brainstorming and discussion. 


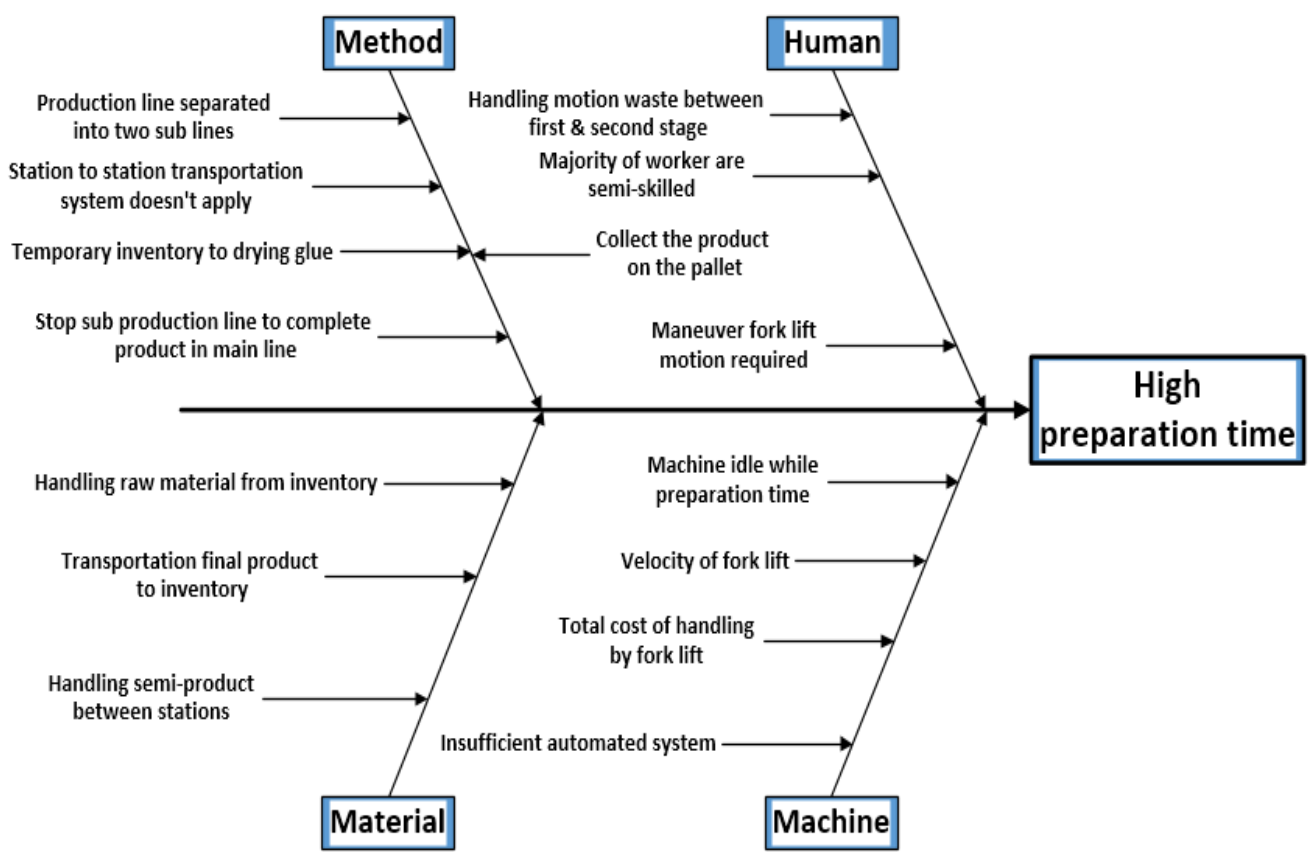

Fig. 7: Cause and effect diagram of preparation time problem

Fig. 8 show the cause-effect diagram in defect sources stated are examined below in order of process. The category of the defect source mentioned are 4M (Machine, methods, Man, materials) is indicated in parentheses. It is developed through brainstorming and discussion. The main causes are:

- Only visual inspection followed.

- No classification of defects and causes.

- Not inspection after each stage separately.

- Unsynchronized tuber and bottomar system.

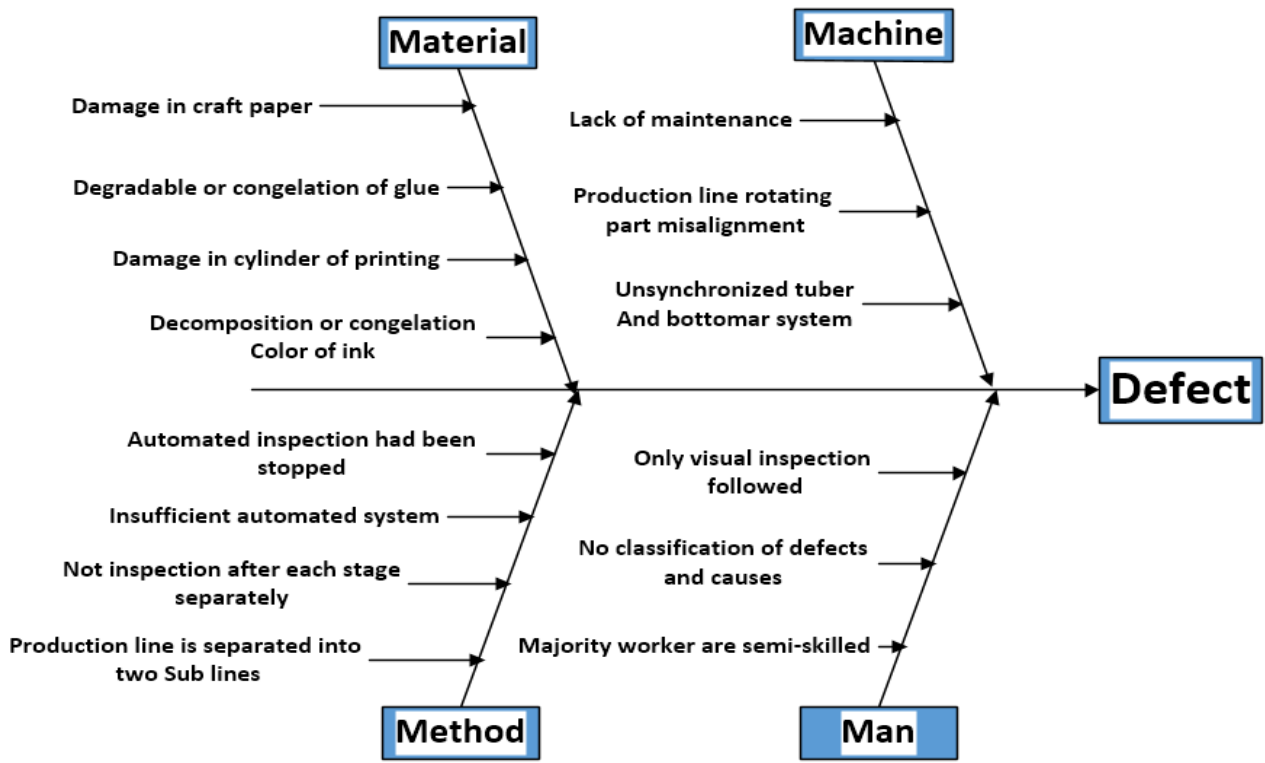

Fig. 8: Cause and effect diagram of defect in cement bags

The data collected show that stopped operating in second stage as a result of the semi-product isn't accessible when beginning work. The stopped operating about $45 \mathrm{~min}$ to collect 2 pallets and handling. Table 5 below shows summarized of stopped operating and probability of happens during this situation, the average of probability of happens this stopped is $25.81 \%$. This stopped working in start second stage about $11.61 \mathrm{~min}$ (696.6 secs) at the beginning of shift until the semi-product is complete in the first stage, in addition to the preparation time before second stage of 36 secs in the production line. 
Implementation of Lean Six Sigma (LSS) Techniques in Small and Medium Enterprises (SMEs) to ..

Table 4: Summarized of stopped working and probability of occurs

\begin{tabular}{|c|c|c|c|c|}
\hline Week & Workdays & Total shift & No. of stops & Probability \\
\hline 1 & 6 & 12 & 3 & 25.00 \\
\hline 2 & 5 & 10 & 2 & 20.00 \\
\hline 3 & 6 & 11 & 3 & 27.27 \\
\hline 4 & 6 & 12 & 5 & 41.67 \\
\hline 5 & 6 & 11 & 3 & 27.45 \\
\hline 6 & 6 & 11 & 0 & 0.00 \\
\hline 7 & 6 & 12 & 3 & 21.43 \\
\hline 8 & 7 & 14 & 24 & 25.81 \\
\hline
\end{tabular}

\subsection{Phase 4: Improve}

At this part, it has been identified clearly the most causes for each kind of wastes, expected solutions, needed actions, interval, and others. Corrective actions are started immediately as requested by management. The Improve section is wherever the planned action to reduce the probability of reoccurrence for these problems. in order to enhance and reduce the preparation time and therefore the setup time between first stage and second stage and reducing the potential to prevent operating the second stage time, the system or process should be automatic the transporting of product from the end of the first stage to the start of the second stage directly using an industrial conveyor.

It is working while not collect time, reduce the time needed for transfer, and therefore the eliminate shut down in shift starting within the unavailable of semi-product from the previous stage, therefore the time is adjusted a transport by $50 \%$ or $18 \mathrm{secs}$ the percentage of 4.57 take pleasure in NVA, whereas reduces shut down second stage of $25.81 \%$ time $(696 \mathrm{sec}$ ) to zero. Table 6 below shows the number of revenue from this reduce the waste time. the increase annual production 335,700 bags with percent $4.25 \%$, whereas the overall annual revenue is $\$ 8952$.

Table 4: The annual revenue of reduce waste time

\begin{tabular}{|c|c|c|c|c|c|c|}
\hline State & $\begin{array}{c}\text { Time } \\
\text { reduce } \\
(\mathrm{sec})\end{array}$ & $\begin{array}{c}\text { Ratio } \\
\text { improvement }\end{array}$ & $\begin{array}{c}\text { Production } \\
\text { increase } \\
/ \text { day }\end{array}$ & $\begin{array}{c}\text { Annual } \\
\text { production }\end{array}$ & $\begin{array}{c}\text { Percentage } \\
\text { Annual revenue } \\
(\$)\end{array}$ \\
\hline Preparation time & 18 & $4.57 \%$ & 55 & 16500 & $0.209 \%$ & 440 \\
\hline $\begin{array}{c}\text { Stop working in second } \\
\text { stage }\end{array}$ & 696.6 & $25.81 \%$ & 1064 & 319200 & $4.04 \%$ & 8,512 \\
\hline
\end{tabular}

In the current state the defects is treated through the applying of maintenance periodic machines and create the screening process happen when each stage of the production stages and improved to be automatic, therefore defects might be reduced nearly $20-25 \%$, the subsequent table 7 shows the number of defective product when the applying of the projected enhancements.

Table 5: The defects in cement bags after appication improvement

\begin{tabular}{|c|c|c|c|c|c|c|}
\hline \multirow[t]{2}{*}{ Month } & \multirow[t]{2}{*}{ Production } & \multirow{2}{*}{$\begin{array}{l}\text { Production after reduce } \\
\text { waste preparation time }\end{array}$} & \multicolumn{2}{|c|}{ Defects } & \multicolumn{2}{|c|}{ Defect ratio } \\
\hline & & & Before & $\begin{array}{c}\text { After } \\
\text { improve }\end{array}$ & Before & After improve \\
\hline January & 7792640 & 7818377 & 62040 & 48081 & $0.796 \%$ & $0.617 \%$ \\
\hline February & 8005980 & 8033955 & 64109 & 49685 & $0.801 \%$ & $0.620 \%$ \\
\hline Average & 7899310 & 7961666 & 63075 & 48883 & $0.799 \%$ & $0.618 \%$ \\
\hline
\end{tabular}

In addition, there's time waste when a defective product passes within the early stages of industrial process and continue in production line on the subsequent industrial numerous stages to the only real and final inspection station. The saving about \$12,730.61 per year, and also the sigma level after application the proposal of improvement within the processes, the defect per million opportunity (DPMO) is 6188.26 defect with defects ratio is $0.618 \%$. the level of accuracy in processes is 99.38 to increase regarding $0.18 \%$. However, the sigma level during this case is 4.00 , the sigma level increase 0.09 with $\% 2.31 \%$.

Table 8 presents the many improvements within the key performance metrics after implementation of Lean Six sigma (LSS) methodology. The key performance used for comparison the results when implementing the LSS included: Defect Rate, process capability index (Cpk), first time yield, OEE, and sigma level. 
Table 8: Comparison between before and after improvement

\begin{tabular}{|c|c|c|c|c|}
\hline No. & \multicolumn{2}{|r|}{ Key performance } & Before improvement & After improvement \\
\hline 1 & \multicolumn{2}{|c|}{ Defect Rate } & 0.799 & 0.618 \\
\hline 2 & \multicolumn{2}{|c|}{ Yield } & 99.20 & 99.40 \\
\hline \multirow[t]{3}{*}{3} & \multirow{3}{*}{$\begin{array}{l}\text { Process } \\
\text { capability }\end{array}$} & Cpk (length) & 1.41 & 1.60 \\
\hline & & Cpk (valve width) & 1.09 & 1.38 \\
\hline & & Cpk (valve other side width) & 1.93 & 2.07 \\
\hline 4 & \multicolumn{2}{|c|}{ Overall equipment effectiveness (OEE) } & 0.454 & 0.543 \\
\hline 5 & \multicolumn{2}{|c|}{ Sigma level } & 3.91 & 4.00 \\
\hline
\end{tabular}

\subsection{Phase 5: Control}

This section is extremely necessary within the lean six sigma implementation, as LSS doesn't only aim to reduce waste and defects however additionally to be able to sustain the improvement that has been made. so as to sustain the achieved results and to prevent degradation within the process performance. Hence, the standardization of the best process parameters setting is required. From time to time, control charts for dimension of cement bags, to check that the product is meeting the required specification.

That to intensify the subsequent points in order to prevent the occurrence of other defects at different stages of production and reduction of waste time:

- Checking the defects at the primary stage in order that defects aren't passed to after the production stage.

- Use the conveyor between 1 st stage and 2 nd stage to reduce the waste time and eliminate finish off in 2 nd stage.

- Inspection information and analysis of defects and classification of causes these defects.

- Training people on the relating to details of production and quality issues moreover as different activities like problem solving and team building.

- Use of control charts and graphs at every process stage to stay the staff aware of the important time performance at the respective stages of production.

\section{Sustainability:}

The main purpose of the lean six sigma methodology isn't only improving the process performance however additionally having the improved results sustained within the long-term. Hence, the standardization of the optimum process parameters setting is needed. so as to sustain the achieved results and to prevent degradation within the machines' performance, a sustainability plan is created as well as checklists. A sample from the sustain arrange for the cutting machine is conferred in Table 9.

Table 9: Sustain plan for the cement bags machine

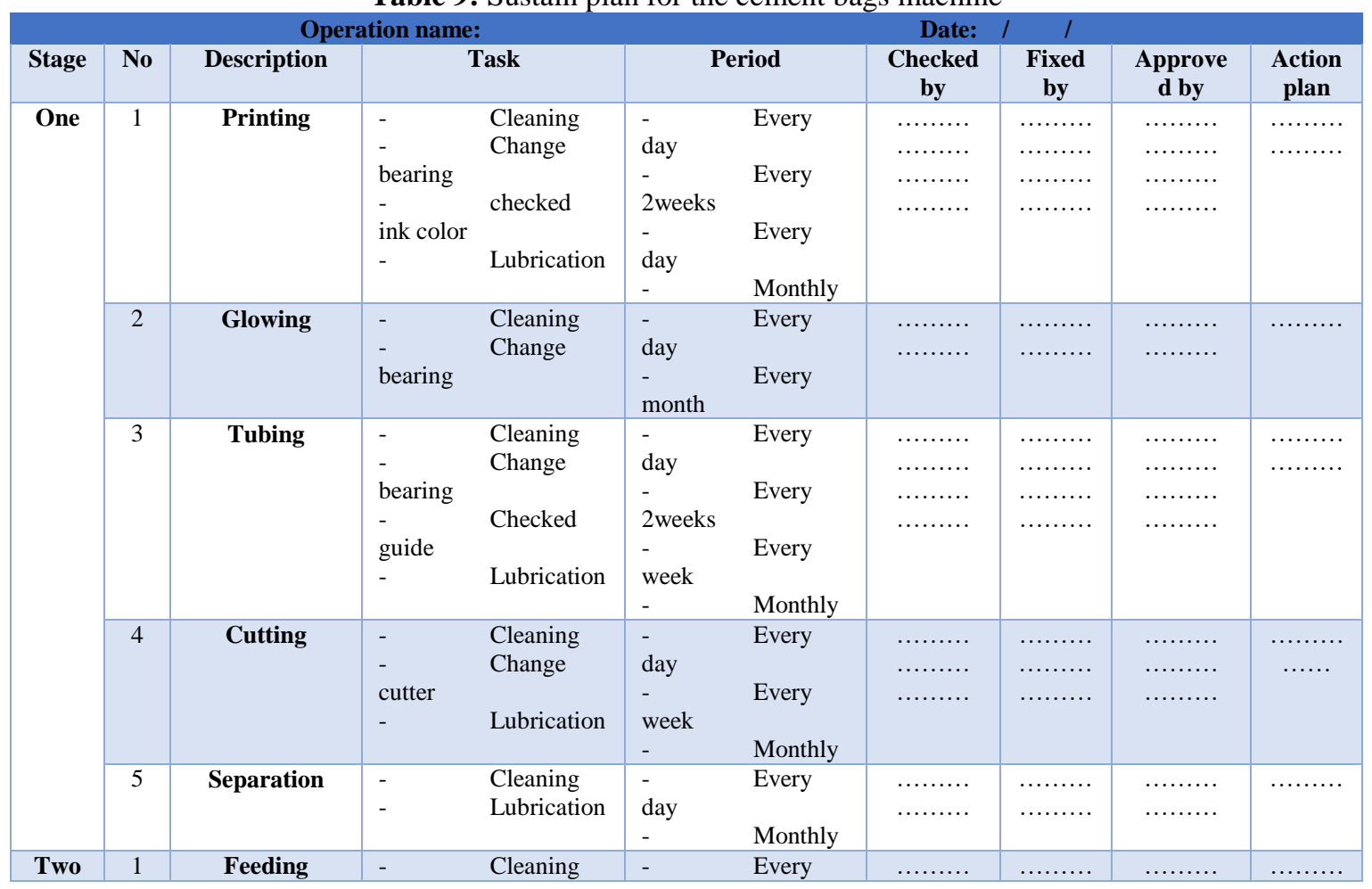




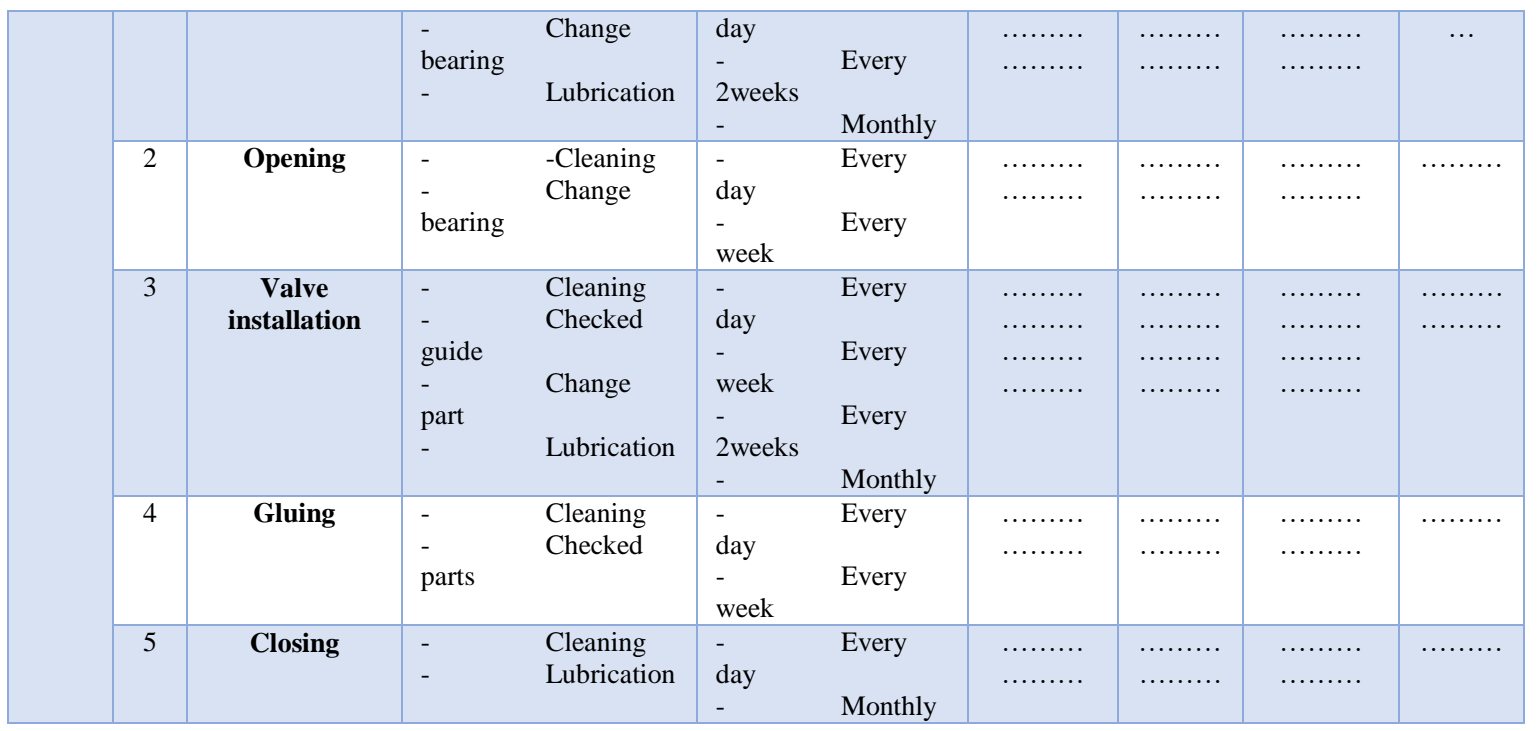

\section{Conclusions}

The following conclusions area unit drawn from this study:

- Lean Six sigma (LSS) will be applied altogether industry areas like business, design, sale, marketing, services and procures quite many benefits.

- The implementation of Lean Six letter of the alphabet (LSS) provided associate impetus for establishing best apply within the company.

- a significant improvement was discovered within the key performance metrics (DPU, process capability, yield, OEE) when implementation of the lean six sigma (LSS).

- Reduction of the preparation time by $4.57 \%$, the rise of annual production is over to 335,700 bags with \% of $4.25 \%$.

- The implementation of the lean six sigma (LSS) has resulted in savings of around $\$ 8,952$ from reduction of waste time and $\$ 12,730.61$ from defects reduction; the overall is $\$ 21,682.61$ annually.

- Increase within the level of sigma level percentage $2.3 \%$ from 3.91 to become 4.00 , and increase within the profits of the company

- Increase within the overall instrumentation effectiveness (OEE) percentage $20 \%$ from 0.45 to become 0.54 .

\section{References}

[1] Atmaca E., and Girenes S. S., 2011, "Lean Six Sigma methodology and application,” Qual. Quant., 47(4), pp. 2107-2127.

[2] Fitzmaurice I., 2010, "The effects of implementing a Lean Six Sigma tool , Visual Process Controls , to improve month-end activities in a finance department - An Empirical Case Study," National University of Ireland.

[3] Mandahawi N., Fouad R. H., and Obeidat S., 2012, "An Application of Customized Lean Six Sigma to Enhance Productivity at a Paper Manufacturing Company,” Jorden J. Mech. Ind. Eng., 6(1), pp. 103-109.

[4] Jie J. C. R., Kamaruddin S., and Azid I. A., 2014, "Implementing the Lean Six Sigma Framework in a Small Medium Enterprise ( SME ) - A Case Study in a Printing Company," International Conference on Industrial Engineering and Operations Management, pp. 387-396.

[5] Patel R., 2011, "Modeling Lean Six Sigma in the small packaging industry in India," Institute of Technology.

[6] Kumar M., Antony J., Singh R. K., Tiwari M. K., and Perry D., 2006, "Implementing the Lean Sigma framework in an Indian SME : a case study," Prod. Plan. Control, 17(4), pp. 407-423.

[7] Sosen A. A. S., Zohir A. H., and Saleh S. A., 2012, "Improvement of Production Quality by using Six Sigma Technique : Applied Study in the Medical Syringes Factory - Babylon," Tekreet Eng. Scinces, 02, p. 12.

[8] Ghaleb A. A., El-sharief M. A., and El-sebaie M. G., 2014, "Study of Tools, Techniques and Factors used in Lean Six Sigma," Int. J. Sci. Eng. Res., 5(12), pp. 1652-1658.

[9] Hale S. A., 2011, "Lean Transformation and Relocation of Jet Engine Assembly Operations by Libraries," Massachusetts Institute of Technology.

[10] Basavaraj Y., Sreenivasa P. K. V., and R. N. N. V., 2011, "Improvement of process capablity through six sigma and robust design : Case study at an Indian Steel Manufacturing," Int. J. Ind. Eng., 18(9), pp. 482-492.

[11] Ramamoorthy S., 2007, "Lean Six-Sigma Applications in Aircraft Assembly," Wichita State University.

[12] Barnala P., 2011, "Optimization of Operating Parameters of a Material Recovery Facility using Lean Six Sigma Techniques," University of Toledo.

[13] Montgomery D. C., 2009, Introduction to Statistical Quality Control, jo.

[14] Taghizadegan S., 2006, Essentials of Lean Six Sigma, Elsevier Inc.

[15] Paul M. Gibbons, Stuart C. Burgess 2010, "Introducing OEE as a measure of lean Six Sigma capability" Int. J. of Lean Six Sigma, $1(2)$, pp. 134-156

[16] D. Tyagi, “A Review On Issues For Implementation Of Six Sigma By Small And Medium Enterprises,” Int. J. Latest Trends Eng. Technol., vol. 3, no. 4, pp. 94-98, 2014. 